\title{
Supporting Information
}

\section{Phosphorescent Molecular Butterflies with Controlled Potential Energy Surfaces and Their Application as Luminescent Viscosity Sensor}

Chenkun Zhou ${ }^{\dagger}$, Lin Yuan ${ }^{\dagger}$, Zhao Yuan ${ }^{\dagger}$, Nicholas Kelly Doyle ${ }^{\dagger}$, Tristan Dilbeck ${ }^{\S}$, Divya Bahadur ${ }^{\dagger}$, Subramanian Ramakrishnan ${ }^{\dagger}$, Albert Dearden", Chen Huang", Biwu $\mathrm{Ma}^{\dagger+\$_{*}}$

${ }^{\dagger}$ Department of Chemical and Biological Engineering, FAMU-FSU College of Engineering, Tallahassee, Florida 32310

${ }^{+}$Materials Science Program, Florida State University, Tallahassee, Florida 32306

${ }^{\S}$ Department of Chemistry and Biochemistry, Florida State University, Tallahassee, Florida 32306

"Department of Scientific Computing, Florida State University, Tallahassee, Florida 32306 


\section{Synthesis and Characterization}

2-phenylpyridine, 1-phenylisoquinoline and 3, 5-dimethyl pyrazole were purchased from Sigma-Aldrich Co. while 3-(tert-butyl)-5-methyl-pyrazole were prepared following literature procedures. ${ }^{1}$

All procedures involving Platinum species were carried out in inert gas atmosphere in spite of the air stability of the complexes, the main concern being the oxidative and thermal stability of intermediates during the reactions. The platinum complexes 2, 3 were synthesized by reacting $\left(\mathrm{C}^{\wedge} \mathrm{N}\right) \mathrm{Pt}(\mu-\mathrm{Cl})_{2} \mathrm{Pt}\left(\mathrm{C}^{\wedge} \mathrm{N}\right)^{2}($ BppyPtPZDMe (2): $\mathrm{C}^{\wedge} \mathrm{N}=$ 2-phenylpyridine; BpiqPtPZMetBu (3): $\mathrm{C}^{\wedge} \mathrm{N}=1$-phenylisoquinoline) with a given pyrazolate ligand, following literature procedures. ${ }^{3}$ The products were purified by column chromatography with dichloromethane as the eluent and recrystallized from methanol/dichloromethane. ${ }^{1} \mathrm{H}$ NMR and mass spectrometry were used to characterize the synthesized products. ${ }^{1} \mathrm{H}$ NMR spectra were obtained at room temperature on Bruker AVANCE III NMR Spectrometers with a $500 \mathrm{MHz}$ Bruker magnet. All chemical shifts $(\delta)$ were reported in ppm relative to tetramethylsilane (TMS). Mass spectrometric measurements were performed on a Autoflex III L200 Time-of-flight (TOF) mass spectrometer with matrix-assisted laser desorption/ionization (MALDI). 


\section{Characterization}

BppyPtPZDMe (2) Yield 22.5\%. ${ }^{1} \mathrm{H}$ NMR (500 MHz, $\mathrm{CDCl}_{3}$ ), ppm: 8.46-8.38 (m, 2H total), $7.70(\mathrm{td}, J=8.0 \mathrm{~Hz}, 1.5 \mathrm{~Hz}, 2 \mathrm{H}), 7.58(\mathrm{~d}, J=8.0 \mathrm{~Hz}, 2 \mathrm{H}), 7.41-7.39$ $(\mathrm{m}, 2 \mathrm{H}), 7.07-6.91(\mathrm{~m}, 8 \mathrm{H}), 6.05-5.89(\mathrm{~m}, 2 \mathrm{H}$ total $), 2.62-2.26(\mathrm{~m}, 12 \mathrm{H})$. Mass: $\mathrm{C}_{32} \mathrm{H}_{30} \mathrm{~N}_{6} \mathrm{Pt}_{2}$ : Calculated: 888.18; found: 888.47.

${ }^{1} \mathrm{H}$ NMR $\left(500 \mathrm{MHz}, \mathrm{CDCl}_{3}\right)$

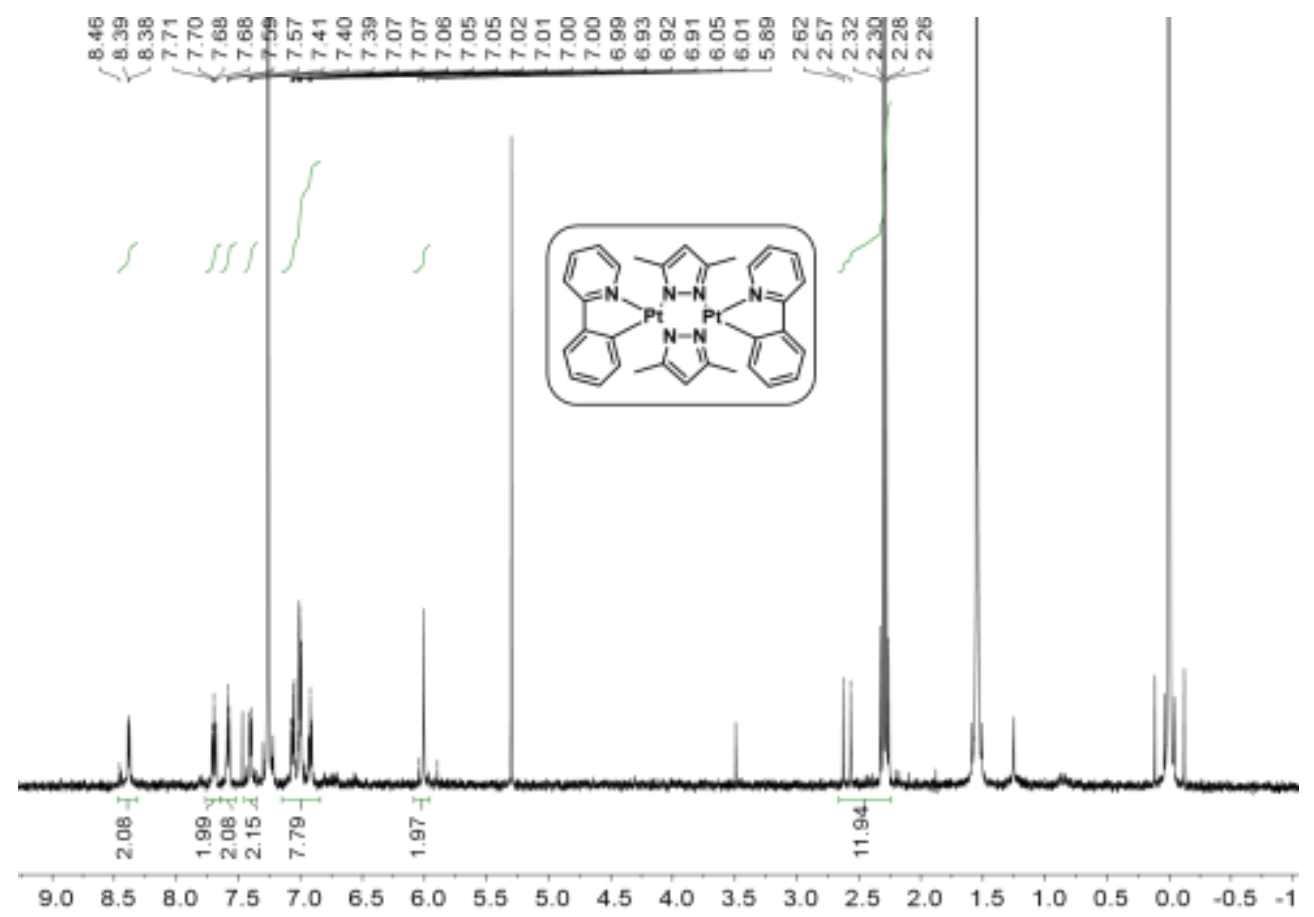


BpiqPtPZMetBu (3) Yield 19.2\%. ${ }^{1} \mathrm{H}$ NMR (500 MHz, $\left.\mathrm{CDCl}_{3}\right)$, ppm: 8.66 (d, $J=8.7 \mathrm{~Hz}, 2 \mathrm{H}), 8.00(\mathrm{~d}, J=6.4 \mathrm{~Hz}, 2 \mathrm{H}), 7.89(\mathrm{dd}, J=7.3 \mathrm{~Hz}, 2.0 \mathrm{~Hz}, 2 \mathrm{H}), 7.54-7.53$ (m, 2H), 7.48-7.41 (m, 6H), 7.04-6.98 (m, 6H), $6.06(\mathrm{~s}, 2 \mathrm{H}), 2.44(\mathrm{~s}, 6 \mathrm{H}), 1.30(\mathrm{~m}$, 18H). Mass: $\mathrm{C}_{46} \mathrm{H}_{46} \mathrm{~N}_{6} \mathrm{Pt}_{2}$ : Calculated: 1072.31; found: 1072.14.

${ }^{1} \mathrm{H} \mathrm{NMR}\left(500 \mathrm{MHz}, \mathrm{CDCl}_{3}\right)$

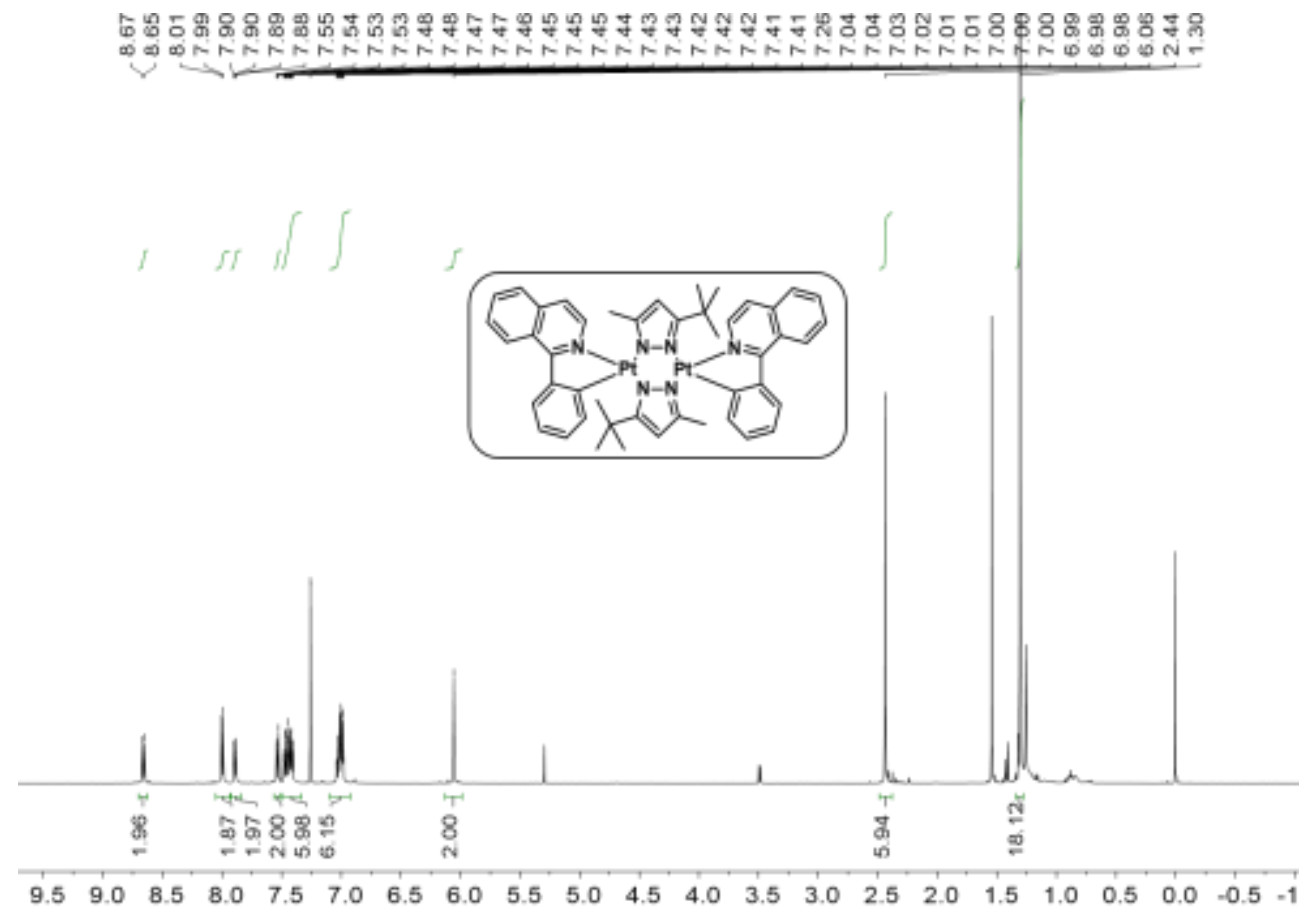

\section{Sample Preparation}

Low concentration solution samples were prepared by dissolving molecules $\mathbf{1 - 3}(0.2$ $\mu \mathrm{mol})$ in small amount of dichloromethane to obtain absorption, steady state phosphorescence, and time-resolved emission in liquid solutions. BppyPtPZDMe $(0.2 \mu \mathrm{mol})$ was dissolved in small amount of tridecane, tetradecane, pentadecane, hexadecane, heptadecane, and octadecane to obtain steady state phosphorescence upon viscosity. Solid samples were placed in quartz cuvette to obtain steady state phosphorescence and were sealed between glass sheets to obtain quantum yield and time-resolved emission. 


\section{Photophysical Properties}

Absorption spectrum measurements. The absorption spectra of three compounds were measured at room temperature by using a Cary 5000 UV-Vis-NIR spectrometer.

Steady-state photoluminescence studies. Steady-state photoluminescence spectra of three compounds were obtained at room temperature on a Varian Cary Eclipse fluorescence spectrophotometer. Samples were excited at $360 \mathrm{~nm}$ (BFPtPZ, 1), 380 nm (BppyPtPZDMe, 2), and $420 \mathrm{~nm}$ (BpiqPtPZMetBu, 3) respectively using a xenon flash lamp.

Photoluminescence quantum efficiencies (PLQEs). For liquid solution samples, absorbance at the excitation wavelength was kept below 0.1 to minimize the inner-filter effect. The PLQEs were determined by comparing the integrated area of the corrected emission spectrum with that of the reference-quinine bisulfate $(\varphi \mathrm{f}=$ 0.546 in $\left.1 \mathrm{~N} \mathrm{H}_{2} \mathrm{SO}_{4}\right)$ for $\mathbf{1}, 2$ and Rhodamine $101(\varphi \mathrm{f}=1.0)$ for 3. For solid samples, PLQEs were acquired using an integrating sphere incorporated into a spectrofluorometer (FLS980, Edinburgh Instruments). The scattering sample used was the sample holder without sample present. Absorption/scatter at the excitation wavelength and emission from the sample/reference were acquired under the same instrument settings. The absolute quantum efficiencies were then calculated by using the Edinburg L980 software package.

Time-resolved photoluminescence. For liquid solution samples, time-resolved emission data were collected by using time-correlated single photon counting on a Horiba JY Fluoromax-4 Fluorometer. (Figure S1) Samples were excited with $370 \mathrm{~nm}$ $(\mathbf{1}, \mathbf{2})$ and $460 \mathrm{~nm}(\mathbf{3})$ pulsed diode lasers. Emission counts were monitored at $464 \mathrm{~nm}$, $618 \mathrm{~nm}(\mathbf{1}), 494 \mathrm{~nm}, 596 \mathrm{~nm}(\mathbf{2})$, and $635 \mathrm{~nm}, 736 \mathrm{~nm}(3)$. For solid samples, time-resolved emission data were collected at room temperature using an Edinburgh FLS980 spectrometer. Samples were excited with the indicated pulsed excitation source and directed through a flip mirror to the sample. Emission from the sample 
was first passed through an indicated long-pass color filter, then a single grating (1800 1/mm, $500 \mathrm{~nm}$ blaze) Czerny-Turner monochromator (21 nm bandwidth), and finally detected by a Peltier-cooled Hamamatsu R928 photomultiplier tube. The dynamics of emission decay were monitored by using the FLS980s time-correlated single-photon counting capability (1024 channels; $20 \mu \mathrm{s}$ (1), $10 \mu$ s (2), and $5 \mu$ s (3) window) with data collection for 10,000 counts. Excitation was provided by an Edinburgh EPLED-360 ps pulsed LED (368.6 nm, $891.8 \mathrm{ps}$ fwhm) operated at $50 \mathrm{KHz}(\mathbf{1})$ and $1000 \mathrm{kHz}$ (2) and an Edinburgh EPL-405 ps pulsed diode laser (400.4 nm, 57.6 ps fwhm) operated at $200 \mathrm{kHz}$ (3). Emission counts were monitored at $484 \mathrm{~nm}$ (1) and $525 \mathrm{~nm}$ (2) with a $395 \mathrm{~nm}$ long pass filter in front of the detector and at $631 \mathrm{~nm}$ (3) with a $435 \mathrm{~nm}$ long pass filter. The average lifetime was obtained from the multi exponential decays.

\section{Viscosity Measurements}

Viscosity measurements were performed on a Malvern Gemini 150 Constant Stress Rheometer, equipped with a coneplate geometry (40 $\mathrm{mm}$ of diameter, $4^{\circ}$ cone angle, and $1 \mathrm{~mm}$ gap). Peltier device was used to fix temperature. All samples were kept in equilibrium at the measuring temperature for 5-10 $\mathrm{min}$ before measurements.

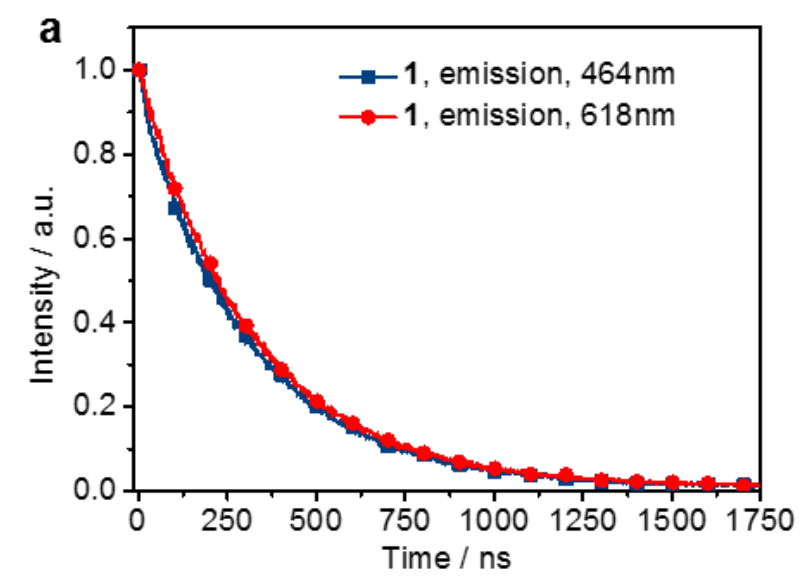



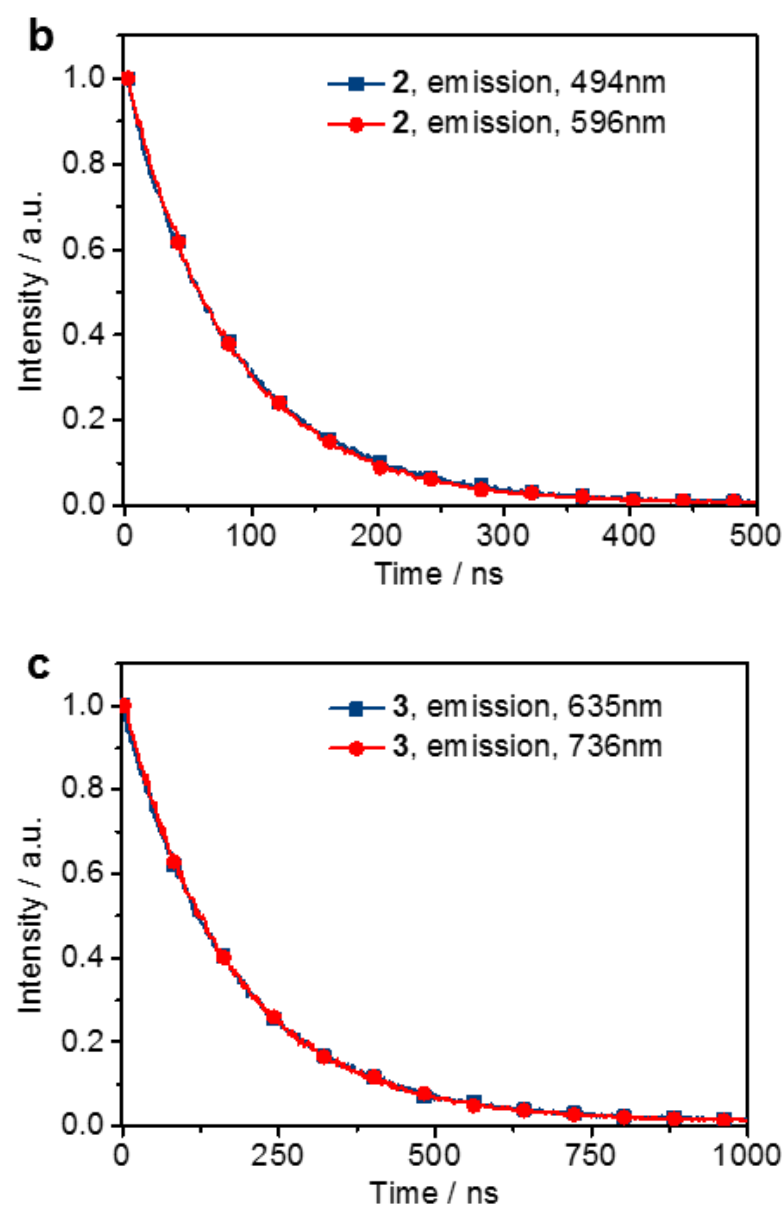

Figure S1. Excited state decay curves of $10^{-4}$ M 1-3 in DCM monitored at wavelengths of $464 \mathrm{~nm}$ and $618 \mathrm{~nm}(\mathbf{1}), 494 \mathrm{~nm}$ and $596 \mathrm{~nm}(\mathbf{2}), 635 \mathrm{~nm}$ and $736 \mathrm{~nm}(3)$.

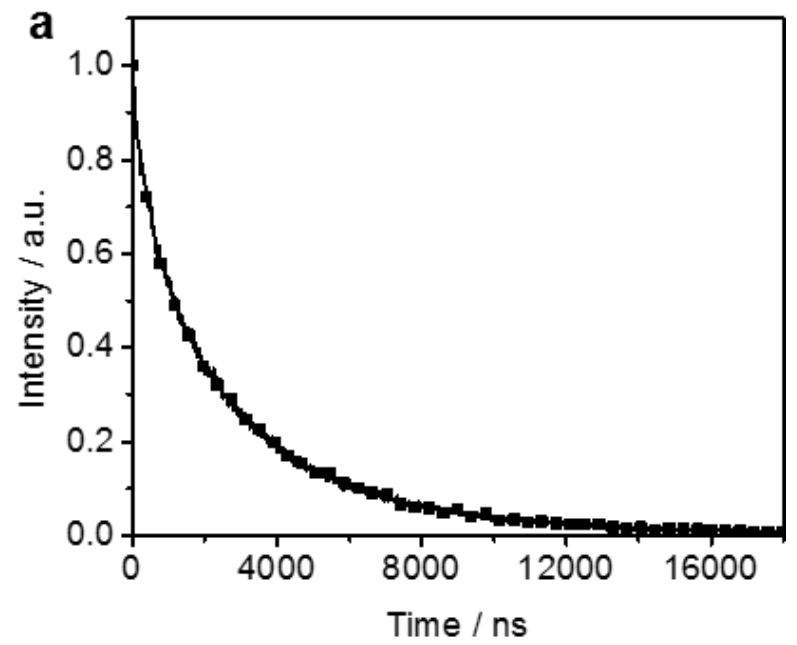



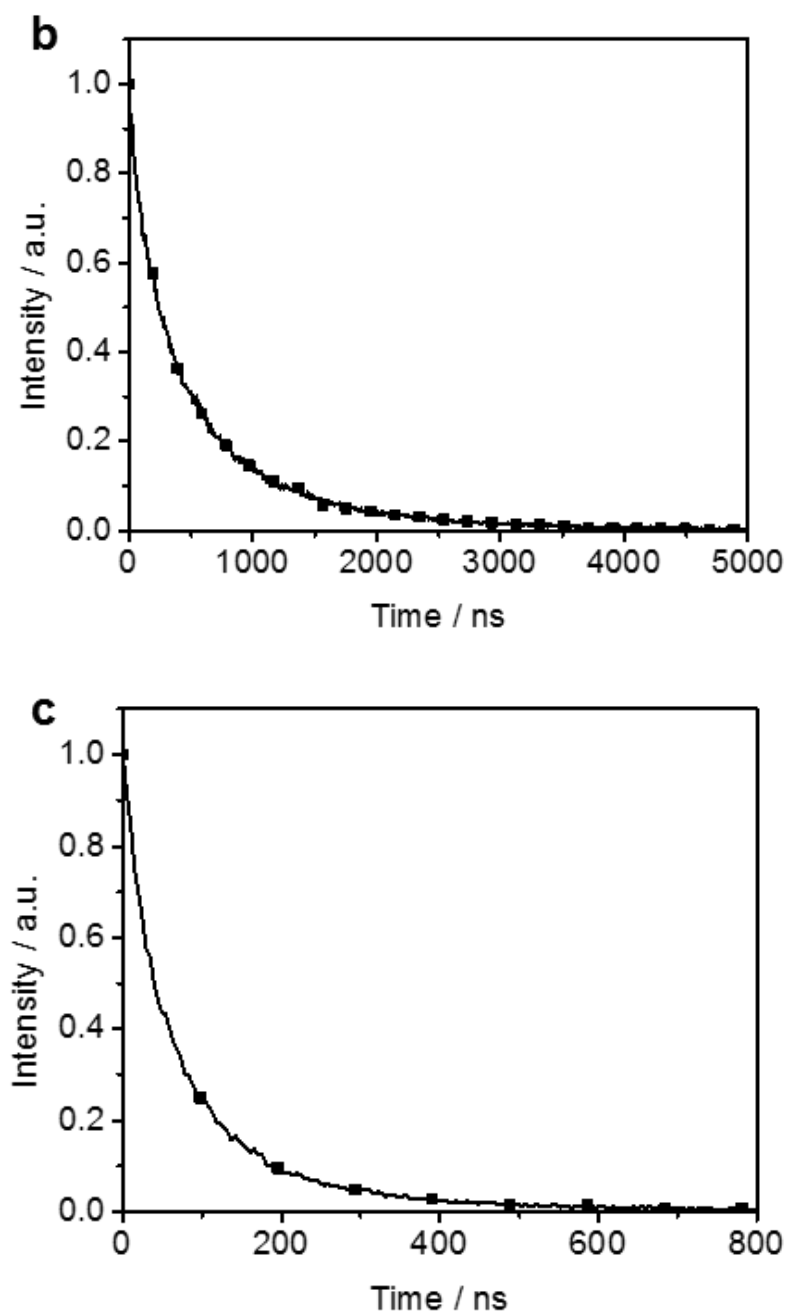

Figure S2. Excited state decay curves of 1-3 in solid state monitored at wavelengths of $484 \mathrm{~nm}(1), 525 \mathrm{~nm}(2)$, and $631 \mathrm{~nm}(3)$. 
Table S1. Quantum yield and emission lifetimes of molecule 1-3 in solid state

\begin{tabular}{ccc}
\hline & Quantum yield/ \% & Lifetime/ $\mu$ s \\
\hline $\mathbf{1}$ & 85 & 3.1 \\
$\mathbf{2}$ & 44 & 0.71 \\
$\mathbf{3}$ & 5.7 & 0.13 \\
\hline
\end{tabular}
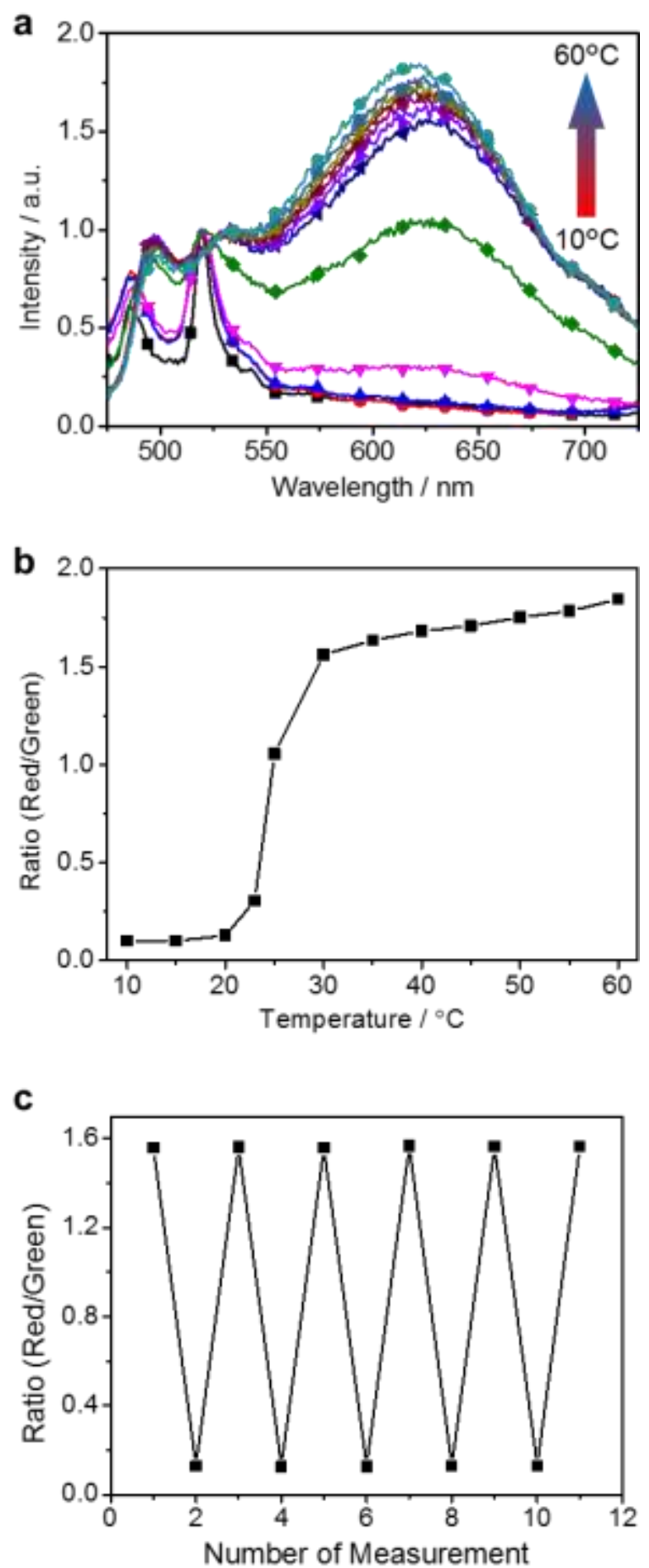

Figure S3. a) The normalized emission spectra of BppyPtPZDMe in octadecane at various 
temperatures from $10^{\circ} \mathrm{C}$ to $60^{\circ} \mathrm{C}$. b) A correlation between the temperature and the ratio of luminescent intensities of peak red emission and green emission of BppyPtPZDMe in octadecane. c) Multiple-run reversibility experiments of the luminescence responses of BppyPtPZDMe to temperature variation in octadecane.

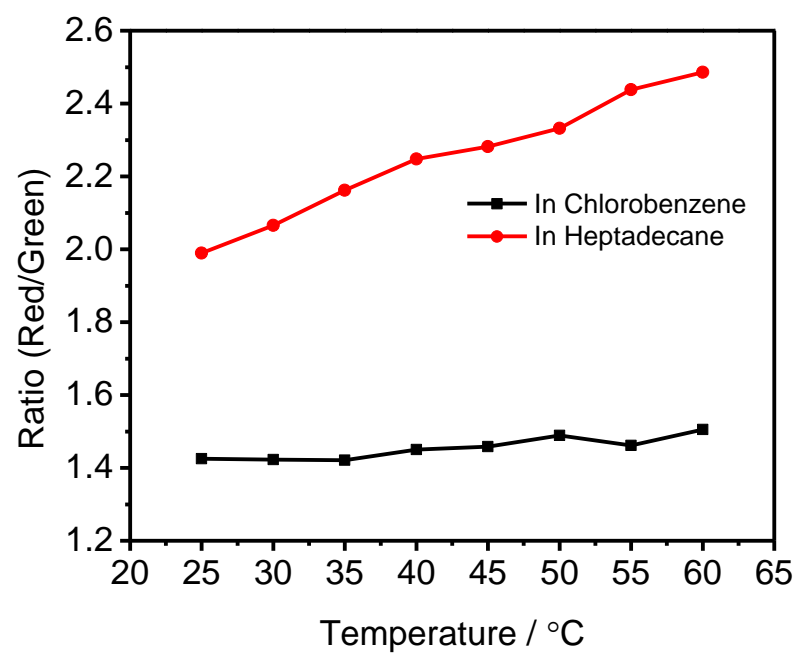

Figure S4. The correlation between the viscosity and the ratio of red to green emission of BppyPtPZDMe in chlorobenzene and heptadecane. 

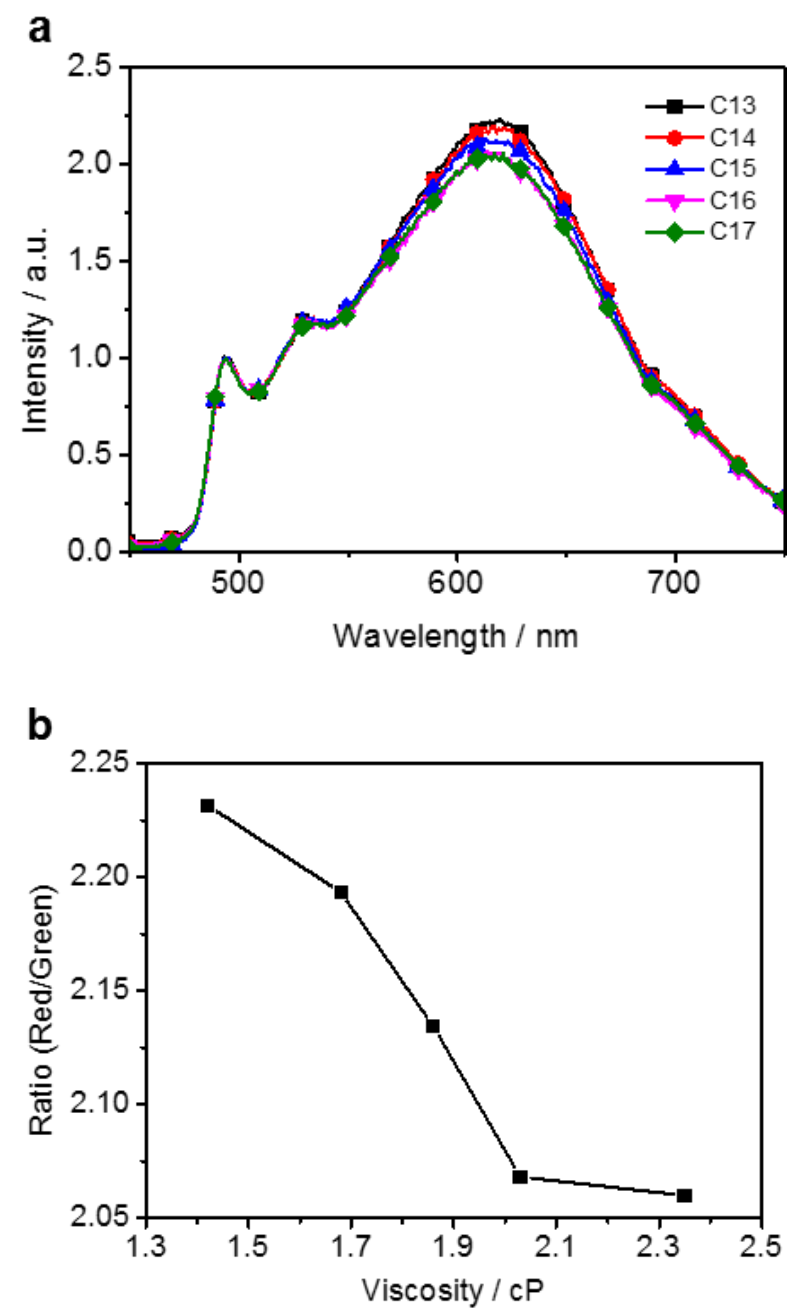

Figure S5. a) The normalized emission spectra of BppyPtPZDMe $\left(2 \times 10^{-4} \mathrm{M}\right)$ in tridecane, tetradecane, pentadecane, hexadecane, and heptadecane. b) A correlation between the viscosity and the ratio of red to green emission of BppyPtPZDMe in tridecane, tetradecane, pentadecane, hexadecane, and heptadecane.

\section{DFT Calculations}

Unrestricted Kohn-Sham DFT calculations were performed using the NWChem software ${ }^{4}$. To remove the core electrons, the effective core potentials and the corresponding valene-double zeta basis sets due to Stevens et al. ${ }^{5,6}$ were employed. $\mathrm{B} 3 \mathrm{LPY}^{7,8}$ exchange-correlation functional was used. To calculate the triplet and singlet potential energy surfaces, the bond length between the two Pt atoms was fixed, while the other atoms were relaxed. For the molecule 1, our results, including the barrier height between the $\mathrm{T}_{1 \mathrm{a}}$ and $\mathrm{T}_{1 \mathrm{~b}}$ states, as well as the energies of 
phosphorescence spectra, agree very well with what were reported in the previous work. $^{9}$ 


\section{Reference}

1. Fernandezcastano, C.; Focesfoces, C.; Jagerovic, N.; Elguero, J., Journal of Molecular Structure 1995, 355, 265-271.

2. Brooks, J.; Babayan, Y.; Lamansky, S.; Djurovich, P. I.; Tsyba, I.; Bau, R.; Thompson, M. E., Inorganic Chemistry 2002, 41, 3055-3066.

3. Ma, B. W.; Li, J.; Djurovich, P. I.; Yousufuddin, M.; Bau, R.; Thompson, M. E., Journal of the American Chemical Society 2005, 127, 28-29.

4. Valiev, M.; Bylaska, E. J.; Govind, N.; Kowalski, K.; Straatsma, T. P.; Van Dam, H. J. J.; Wang, D.; Nieplocha, J.; Apra, E.; Windus, T. L.; de Jong, W., Computer Physics Communications 2010, 181, 1477-1489.

5. Stevens, W. J.; Basch, H.; Krauss, M., Journal of Chemical Physics 1984, 81, 6026-6033.

6. Stevens, W. J.; Krauss, M.; Basch, H.; Jasien, P. G., Canadian Journal of Chemistry-Revue Canadienne De Chimie 1992, 70, 612-630.

7. Becke, A. D., Physical Review A 1988, 38, 3098-3100.

8. Lee, C. T.; Yang, W. T.; Parr, R. G., Physical Review B 1988, 37, 785-789.

9. Saito, K.; Nakao, Y.; Sakaki, S., Inorganic Chemistry 2008, 47, 4329-4337. 